\title{
Contributions of Prefrontal Cortex to Recognition Memory: Electrophysiological and Behavioral Evidence
}

\author{
Diane Swick \\ University of California, Davis, and Veterans Affairs \\ Medical Center, Martinez, California
}

\author{
Robert T. Knight \\ University of California, Berkeley, and Veterans Affairs \\ Medical Center, Martinez, California
}

\begin{abstract}
To clarify the involvement of prefrontal cortex in episodic memory, behavioral and event-related potential (ERP) measures of recognition were examined in patients with dorsolateral prefrontal lesions. In controls, recognition accuracy and the ERP old-new effect declined with increasing retention intervals. Although frontal patients showed a higher false-alarm rate to new words, their hit rate to old words and ERP old-new effect were intact, suggesting that recognition processes were not fundamentally altered by prefrontal damage. The opposite behavioral pattern was observed in patients with hippocampal lesions: a normal false-alarm rate and a precipitous decline in hit rate at long lags. The intact ERP effect and the change in response bias during recognition suggest that frontal patients exhibited a deficit in strategic processing or postretrieval monitoring, in contrast to the more purely mnemonic deficit shown by hippocampal patients.
\end{abstract}

Human memory is not a monolithic phenomenon but rather is composed of different subsystems that are implemented by separate brain regions. Explicit or declarative memory, the ability to recall some event or recognize a particular stimulus, is dependent on medial temporal lobe (MTL), diencephalic, and basal forebrain structures (ZolaMorgan \& Squire, 1993). An important (although disputed) subdivision of memory is the distinction between episodic memory for personally experienced events and semantic memory for facts and general world knowledge (Tulving, 1983). Neuropsychological studies have established the importance of the frontal lobes in specific types and aspects of episodic memory (Luria, 1966; Milner, 1964), including free recall (Incisa della Rocchetta \& Milner, 1993; Janowsky, Shimamura, Kritchevsky, \& Squire, 1989; Jetter, Poser, Freeman, \& Markowitsch, 1986), memory for spatiotemporal context, such as source (Janowsky, Shimamura, \& Squire, 1989) and temporal order (McAndrews \& Milner, 1991; Shimamura, Janowsky, \& Squire, 1990), and the use of encoding and retrieval strategies (Gershberg \& Shimamura, 1995; Mangels, 1997; Stuss et al., 1994). When

Diane Swick, Department of Neurology and Center for Neuroscience, University of California, Davis, and Veterans Affairs Medical Center, Martinez, California; Robert T. Knight, Department of Psychology, University of California, Berkeley, and Veterans Affairs Medical Center, Martinez, California.

This work was supported by Grants NS21135 and PO NS17778 from the National Institute of Neurological Disease and Stroke and by Grant DC03023 from the National Institute of Deafness and Communication Disorders. We thank Marta Kutas and Anders Dale for providing their eyeblink correction algorithm, Clay Clayworth for assistance in preparing the figures, and Debby Burke, Karen Chen, and Donatella Scabini for helpful discussions.

Correspondence concerning this article should be addressed to Diane Swick, Department of Neurology, Veterans Affairs Medical Center, 150 Muir Road, Martinez, California 94553. Electronic mail may be sent to diane@ebire.org. patients with frontal lobe damage are given more support for retrieval, as in tests of cued recall and recognition memory, they are either not impaired or impaired to a lesser degree (Janowsky, Shimamura, Kritchevsky, et al., 1989; Jetter et al., 1986; Swick \& Knight, 1996). Conversely, amnesic patients with diencephalic or MTL damage are equally impaired on tests of recognition and recall (Haist, Shimamura, \& Squire, 1992).

In the last few years, over 30 functional neuroimaging studies have linked prefrontal cortex to retrieval of information from either semantic or episodic memory (reviewed in Buckner, 1996; Nyberg, Cabeza, \& Tulving, 1996). For example, semantic discrimination tasks (Demb et al., 1995; Kapur et al., 1994), word-stem cued recall (Buckner et al., 1995; Squire et al., 1992), recognition of previously studied sentences (Tulving, Kapur, Markowitsch, et al., 1994) or words (Andreasen et al., 1995), and recollection of category exemplars (Shallice et al., 1994) all activate subregions of left and right prefrontal cortex. One difficulty in establishing the functional role of these prefrontal activations is whether they are directly related to episodic encoding and retrieval or are more closely associated with retrieval attempt (Kapur et al., 1995), lexical-semantic processing, working memory, and the use of strategies. Because frontal lesioned patients are not amnesic, their pattern of performance on memory tests suggests the latter interpretation (Janowsky, Shimamura, Kritchevsky, et al., 1989; Mangels, 1997; Petrides \& Milner, 1982; Stuss et al., 1994; Swick \& Knight, 1996).

Furthermore, the limited temporal resolution of positron emission tomography (PET) precludes it from establishing whether frontal activations reflect processes preceding memory retrieval or postretrieval evaluative processes. Some studies have linked prefrontal blood flow changes to the attempt to remember, regardless of whether the effort was successful (Kapur et al., 1995; Nyberg et al., 1995; Schacter, Alpert, Savage, Rauch, \& Albert, 1996), whereas others have associated retrieval success with greater frontal 
activity (Rugg, Fletcher, Frith, Frackowiak, \& Dolan, 1996; Tulving, Kapur, Markowitsch, et al., 1994).

Unlike hemodynamically based neuroimaging techniques, event-related potentials (ERPs) can clarify the timing of the neural activity mediating memory encoding and retrieval with millisecond temporal resolution. ERPs are the summed activity of synchronized postsynaptic potentials recorded noninvasively from the scalp (Hillyard \& Picton, 1987). Improvements in localizing the neural generators of ERP components have increased their utility as a brain mapping technique (Halgren, Marinkovic, \& Chauvel, 1998; Koles, 1998; Swick, Kutas, \& Neville, 1994).

ERP modulations that precede accurate recognition decisions have been shown to reflect neural activity related to memory retrieval processes, with overlapping contributions from components related to stimulus repetition and target detection (Smith \& Guster, 1993). The ERP word repetition effect (or old-new effect) is a well-characterized phenomenon: incidentally repeated or previously studied words elicit larger positive potentials than new words beginning at 300-500 ms poststimulus and lasting for several hundred milliseconds (reviewed in Rugg, 1995). Neural sources participating in explicit and implicit forms of memory retrieval appear to make differing contributions to the ERP repetition effect (Paller \& Kutas, 1992; Rugg, Roberts, Potter, Pickles, \& Nagy, 1991; Swick \& Knight, 1995, 1997). Under explicit retrieval conditions, old words that are associated with conscious recollection (remember responses) evoke larger positive shifts than items associated with only a general feeling of familiarity (know responses; see Düzel, Yonelinas, Mangun, Heinze, \& Tulving, 1997; Smith, 1993).

ERP studies of verbal recognition memory have used both continuous recognition (Friedman, 1990; Rugg \& Nagy, 1989; Swick \& Knight, 1997) and study-test paradigms (Allan \& Rugg, 1997; Neville, Kutas, Chesney, \& Schmidt, 1986; Rugg \& Doyle, 1992; Van Petten \& Senkfor, 1996). With both of these tasks, the ERP old-new effect shows a voltage distribution that is maximum over central-parietal and posterior temporal scalp electrodes (sometimes with a left greater than right hemisphere asymmetry) and typically smaller over frontal electrodes. However, the neural generators of an ERP component cannot be established by the scalp voltage distribution. Intracranial recordings in epileptic patients can directly observe neural regions active during cognitive tasks. Memory-sensitive ERPs have been recorded in a number of areas, including hippocampus; amygdala; parahippocampal, lingual, and fusiform gyri; superior and middle temporal regions; orbital frontal cortex; and anterior inferior-middle frontal gyri (Guillem, N'Kaoua, Rougier, \& Claverie, 1995; Halgren, Baudena, Heit, Clark, \& Marinkovic, 1994; Halgren, Baudena, Heit, Clark, Marinkovic, \& Chauvel, 1994). Anterior temporal lobectomy reduces the amplitude of the scalp-recorded repetition effect during recognition (R. Johnson, 1995; Rugg et al., 1991; Smith \& Halgren, 1989), but the consequences of frontal lesions on this ERP response are unknown.

The present experiment recorded ERPs from controls and stroke patients with focal unilateral lesions of lateral prefron- tal cortex during a continuous recognition task. The behavioral performance of the frontal patients was compared with that of amnesic patients with unilateral hippocampal damage. Our goals were to determine (a) the necessity of prefrontal cortex for intact behavioral and ERP measures of recognition and (b) whether recognition performance can be dissociated in patients with either lateral prefrontal or hippocampal lesions. If prefrontal cortex is crucial for successful recognition, corresponding decrements in performance and the ERP repetition effect are expected. If prefrontal cortex facilitates the use of strategies during memory tests, a more complicated picture may emerge. Furthermore, if prefrontal cortex and the hippocampal region make differing contributions to recognition memory, a divergent pattern of behavioral results is expected.

\section{Method}

\section{Participants}

Participants were 11 patients with focal prefrontal lesions caused by strokes, 3 patients with hippocampal damage, and 11 agematched controls $(M=60.5$ years, range 25-83). Detailed characteristics of individual patients are given in Table 1. Frontal patients were selected for single unilateral focal lesion, visible on computerized tomography or magnetic resonance imaging scans and caused by infarction in the precentral branch of the middle cerebral artery. Patients with lacunar infarcts or white matter hyperintensities were excluded. Lesions were centered in the posterior portion of Brodmann Areas 9 and 46, but damage extended inferiorly and posteriorly to Areas $6,8,44,45$, and the temporal tip in some patients (see Figures 1 and $2 \mathrm{~A}$ ). Hippocampal lesions $(n=3)$ were due to unilateral posterior cerebral artery infarct; the infarct of patient D.R. was subsequent to spasm after aneurysm rupture. Lesions were centered in posterior hippocampus (Figure 2B), with extent into parahippocampal gyrus $(n=3)$, lingual gyrus $(n=2)$, and lateral temporal neocortex $(n=1)$. Patients with significant medical complications, psychiatric disturbances, substance abuse, multiple neurological events, or dementia were excluded. Lesions were transcribed onto corresponding axial templates and then projected onto a lateral view of the brain by computer software. The controls were also matched for handedness ( 10 right handed, 1 left handed) and education level $(M=13.5, S D=2.0$ years). English was the primary language for all participants. The participants were paid for their participation and signed informed consent statements approved by the Institutional Review Board of the Martinez Veterans Affairs Medical Center and the University of California, Davis.

\section{Stimuli and Procedures}

Stimuli were words and pronounceable nonwords, four to eight letters in length. Words were of moderate to low frequency, less than 30 occurrences per million (Francis \& Kucera, 1982), with a mean of 9.35 per million. Half of the words were concrete, and the other half were abstract. Nonwords were created by altering one to three letters in real words or rearranging their sequence. Two sets of 360 stimuli (180 words and 180 nonwords) were constructed so that half of the participants were exposed to one stimulus set and half to the other set. This was done because all of the participants participated in a separate but parallel study of repetition priming in a lexical-decision task (Swick, 1998). Each stimulus set was divided into eight separate lists (or blocks) that were presented 
Table 1

Summary Data on Each Patient

\begin{tabular}{|c|c|c|c|c|c|c|}
\hline Patient & $\begin{array}{c}\text { Age } \\
\text { (years) }\end{array}$ & $\begin{array}{l}\text { Education } \\
\text { (years) }\end{array}$ & Hemisphere & Handedness & $\begin{array}{c}\text { Year of } \\
\text { onset }\end{array}$ & Aphasia \\
\hline \multicolumn{7}{|c|}{ Frontals } \\
\hline A.A. & 26 & 10 & $\mathbf{L}$ & $\mathrm{L}$ & 1993 & None \\
\hline O.A. & 61 & 13 & $\mathbf{L}$ & $\mathbf{R}$ & 1984 & None \\
\hline J.C. & 68 & 16 & $\mathrm{~L}$ & $\mathrm{R}$ & 1987 & Severe anomic, apraxia of speech \\
\hline J.D. & 65 & 20 & $\bar{L}$ & $\mathrm{R}$ & 1986 & Anomic \\
\hline J.H. & 63 & 12 & $\mathrm{~L}$ & $\mathrm{R}$ & 1982 & Anomic \\
\hline B.K. & 61 & 14 & $\mathrm{~L}$ & $\mathrm{R}$ & 1984 & None \\
\hline K.K. & 32 & 14 & $\mathrm{~L}$ & $\mathrm{R}$ & 1989 & Apraxia of speech \\
\hline A.L. & 63 & 13 & $\mathbf{L}$ & $\mathrm{R}$ & 1980 & Anomic \\
\hline W.R. & 50 & 14 & $\mathrm{~L}$ & $\mathbf{R}$ & 1989 & Broca's \\
\hline R.T. & 77 & 16 & $\mathrm{~L}$ & $\mathrm{R}$ & 1985 & Anomic \\
\hline E.B. & 75 & 12 & $\mathrm{R}$ & $\mathbf{R}$ & 1983 & None \\
\hline$M$ & 58 & 14 & & & & \\
\hline \multicolumn{7}{|c|}{ Hippocampals } \\
\hline C.B. & 73 & 15 & $\mathrm{R}$ & $\mathbf{R}$ & 1966 & None \\
\hline W.M. & 72 & 16 & $\mathrm{~L}$ & $\mathbf{R}$ & 1980 & None \\
\hline D.R. & 44 & 12 & $\mathbf{R}$ & $\mathrm{L}$ & 1992 & None \\
\hline$M$ & 63 & 14 & & & & \\
\hline
\end{tabular}

within one session. The order of these lists was counterbalanced across participants. Ninety items occurred in each block: 22 or 23 words and 22 or 23 nonwords, with all stimuli repeated once within the block. Hence, these 45 items were new the first time they were presented and old the second time they were presented. Stimuli never repeated across blocks. Rest periods were given after each block. Lags (delays) between first and second presentation were $3 \mathrm{~s}$ (from onset of first stimulus to onset of repeated stimulus, 0 intervening items), 6-12 s (1-3 intervening items), and 30-60 s (9-19 intervening items); lags were balanced across blocks. The two shorter delays (Lag 0 and Lag 1-3) assessed short-term memory performance, whereas the longest delay (Lag 9-19) reflected long-term memory (see also Sagar, Sullivan, Gabrieli, Corkin, \& Growdon, 1988). In a behavioral investigation of continuous recognition at short and long delays, age-related declines in performance were observed at lags beyond the range of immediate (or short-term) memory, which was defined as occurring after four intervening items (Poon \& Fozard, 1980). Stimulus duration was $500 \mathrm{~ms}$, and the interstimulus interval was $2500 \mathrm{~ms}$. A practice list of 24 stimuli was also constructed.

The response requirement was to discriminate between new and old items (both words and nonwords) in a continuous recognition memory task. The continuous recognition procedure does not contain a separate encoding phase, therefore participants must alternate between identifying and encoding new stimuli and recognizing old stimuli. Participants were seated in a dim, soundattenuated booth. An asterisk was presented at the center of the screen to signal the start of each block. Participants were told that although some items were not real words, this was not important. They pressed one button for new items and the other button for repeated items, regardless of whether the stimuli were words or nonwords. Participants were instructed to respond as quickly and as accurately as possible by using their left and right thumbs. Hand use was counterbalanced across participants, except for 2 patients with motor deficits (hemiparesis).

\section{ERP Recording}

Electrophysiological signals were recorded with an Electro-Cap (Electro-Cap International, Inc., Eaton, $\mathrm{OH}$ ), with electrode placements (according to the 10-20 International System) at Fpl, Fp2, Fz, F3, F4, F7, F8, Cz, C3, C4, Pz, P3, P4, T3, T4, T5, T6, O1, and $\mathrm{O} 2$ and referred to linked mastoids. Eye movements were monitored by electrodes placed below and lateral to the left eye, also referred to linked mastoids. Signals were amplified $(\times 50,000)$ and filtered $(0.1-100 \mathrm{~Hz})$ through a Grass Neurodata acquisition system (Grass Instruments, West Warwick, RI). The electroencephalogram was continuously digitized at $250 \mathrm{~Hz}$ per channel and stored on tape for subsequent analysis. The recording epoch was $1,024 \mathrm{~ms}$.

\section{Data Analysis}

ERP averages for each stimulus type (word, nonword) and condition (new, Lag 0, Lag 1-3, Lag 9-19) were computed for individual participants; grand averages were computed separately across participants for controls and frontal patients. Trials contaminated by eye movements, excessive peak-to-peak deflection (over $100 \mu \mathrm{V}$ ), and amplifier blocking were automatically rejected from the averaged data. Trials with correctable blinks (free of other artifacts) were corrected with an adaptive filtering algorithm developed by Anders Dale. Difference waveforms were derived by subtracting ERPs to new stimuli from ERPs to repeated stimuli. The data were quantified by computing mean amplitudes and peak amplitudes in defined latency windows in relation to a $100-\mathrm{ms}$ prestimulus baseline.

Statistical analyses were carried out on PC and Macintosh computer systems with repeated measures analyses of variance (ANOVAs). Greenhouse-Geisser corrections for multiple comparisons were used when appropriate; the corrected $p$ values and the uncorrected degrees of freedom are reported. ERP amplitude 
$\begin{array}{lllllll}1 & 2 & 3 & 4 & 5 & 6 & 7\end{array}$

AA ${ }^{7}$ 年

OA ${ }^{7}$.

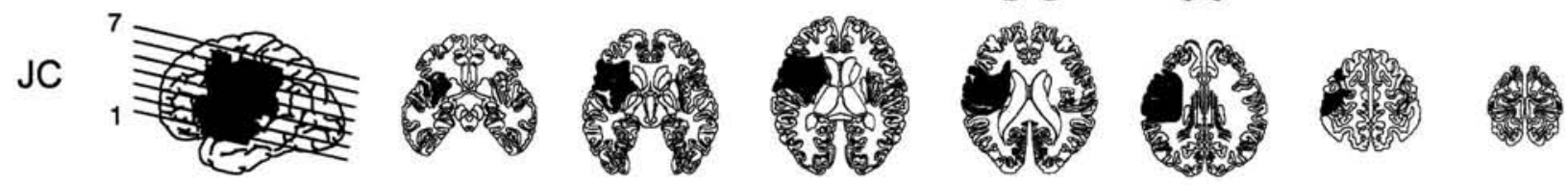

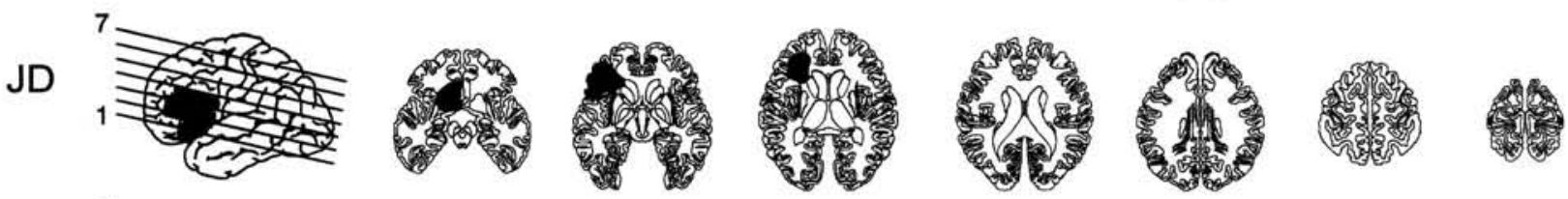

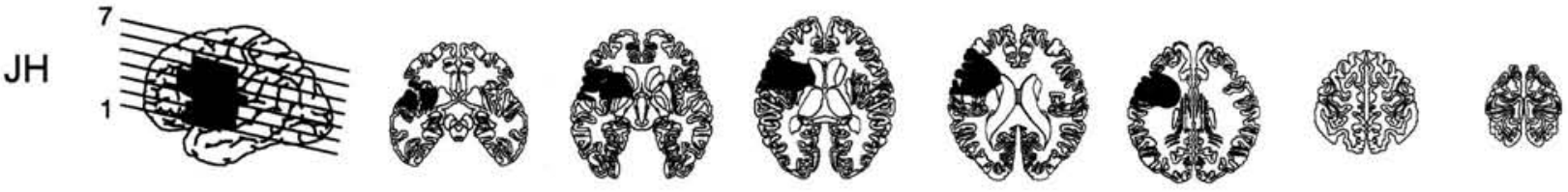

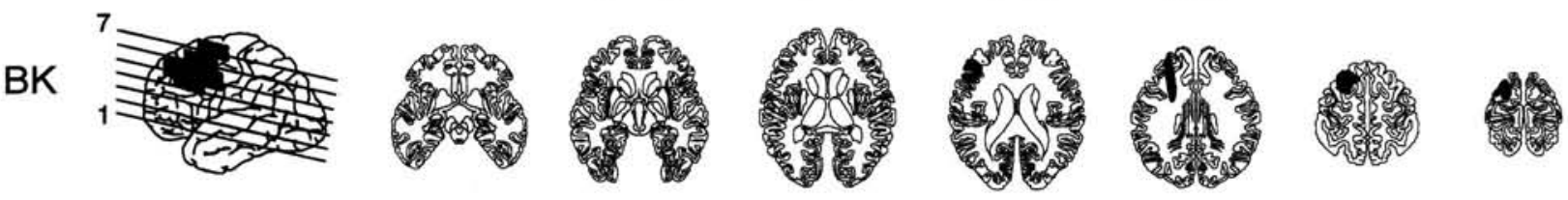

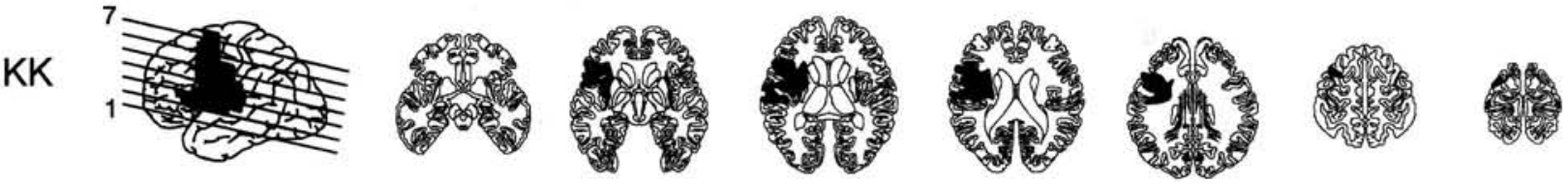

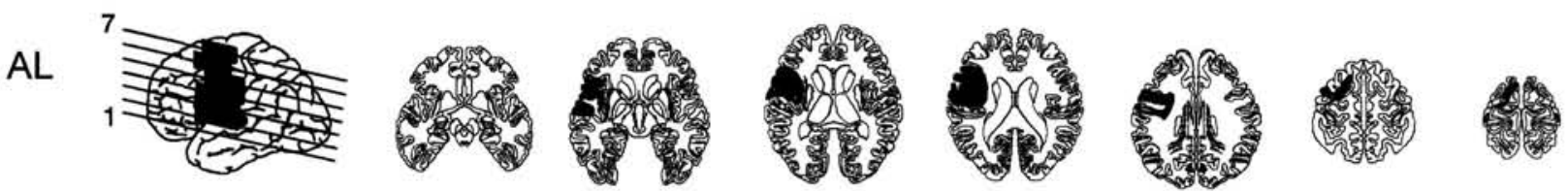

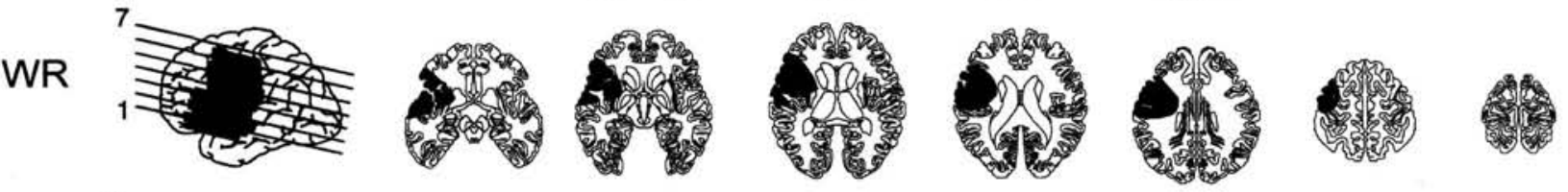

RT ${ }^{7}$ 不

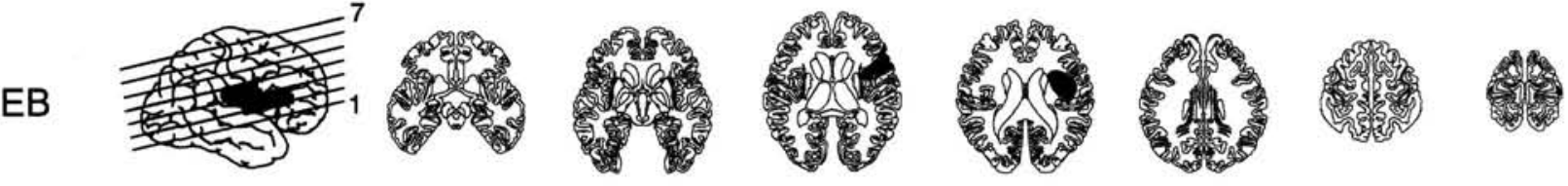

Figure 1. Lesion reconstructions for individual frontal patients (labeled with initials). Lesions were estimated from computerized tomography or magnetic resonance imaging scans and transcribed onto sequential axial templates. Lines through the lateral view show the level of the axial cuts from ventral (1) to dorsal (7). 

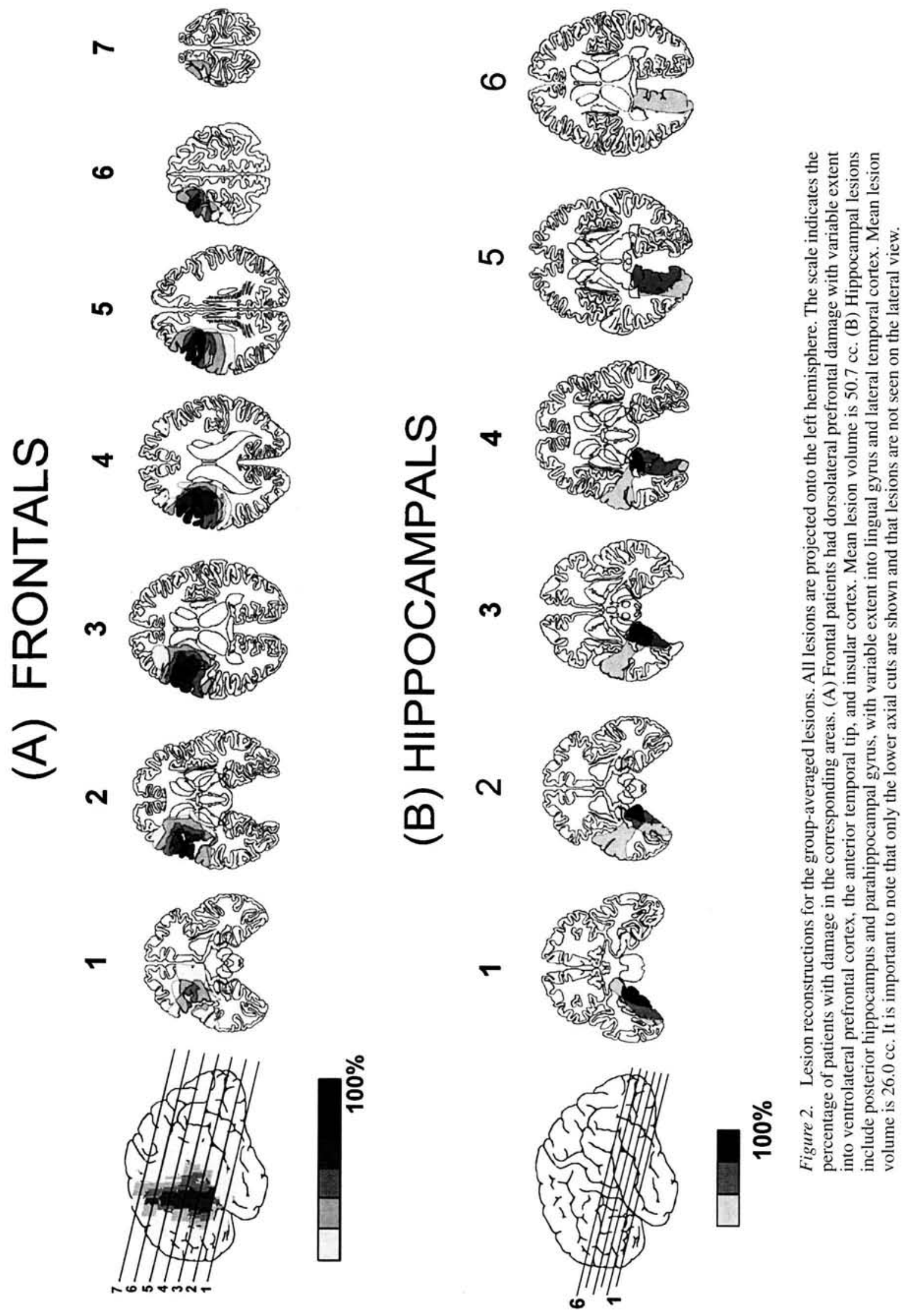
measures were analyzed by stimulus type, condition, group, and electrode. In the ANOVAs for difference waves and responses to old items only (e.g., hits), the variable of condition is referred to as lag (Lag 0, Lag 1-3, Lag 9-19). Differences in scalp distribution across conditions and between groups were also analyzed after normalization of the data (using the first algorithm described by McCarthy \& Wood, 1985). This procedure allows for the possibility that a given scalp distribution effect could be due to multiplicative differences in neural source strength across conditions. Hence, any interaction involving the electrode factor was reported only if significant in the normalized data set. Recognition memory performance was assessed by calculating hits (percentage of correct responses to repeated items), false alarms (percentage of new items incorrectly identified as old), and a corrected recognition measure, hits - false alarms (Snodgrass \& Corwin, 1988). Accuracy and reaction times (RTs) were analyzed by stimulus type, condition (or lag), and group. Planned comparisons (contrasts) or post hoc tests (Fisher's protected least significant difference) were used to further describe significant effects. The corrected $p$ values are reported for these.

\section{Results}

\section{Behavioral Performance}

The analysis of hit rates (Figure $3 \mathrm{~A}$ ) showed that all participants were most accurate for immediately repeated stimuli, and accuracy declined as lag increased: The main effect of lag was, $F(2,40)=25.85, p<.0001$. The results from words are emphasized. Although the hit rate for nonwords tended to be lower (particularly at the longer two lags), neither the main effect of stimulus type, $F(1,20)=$ $3.04, p<.1$, nor the Stimulus Type $\times$ Lag interaction, $F(2$, $40)=2.95, p<.08$, reached significance. Most important, the hit rates of frontal patients and controls did not differ, $F(1,20)=1.81, p>.19$, nor did group interact with lag or stimulus type $(p s>4)$. However, the analysis of false alarms (Figure 3B) revealed a significant main effect of group, $F(1,20)=5.18, p<.05$, and a Stimulus Type $\times$ Group interaction, $F(1,20)=5.00, p<.05$. Frontal patients were more likely to respond incorrectly to new stimuli, with a higher false-alarm rate for words than nonwords, $t(10)=$ $2.63, p<.05$. Because the false-alarm rate was higher in the patients, the corrected recognition score (hits - false alarms; Figure 3C) showed a significant main effect of group, $F(1$, 20) $=7.69, p<.05$, but group did not interact with lag $(p>.14)$. Although the Group $\times$ Lag interaction was not significant, planned comparisons revealed that the patients performed significantly worse than controls at Lag 0 $(p<.05)$ and Lag $1-3(p<.01)$, but not at Lag 9-19 $(p<.1)$. Finally, a measure of response bias $(\beta)$ differed between the two groups, $F(1,20)=4.73, p<.05$, with the frontal patients showing a more liberal response criterion (1.64) than controls (3.59) when words were considered separately. However, $\beta$ for nonwords did not differ significantly $(p>.2)$ between controls (2.99) and frontal patients (2.00).

Analysis of RT data (Figure 3D) revealed that for all conditions, frontal patients were marginally slower than
(A)

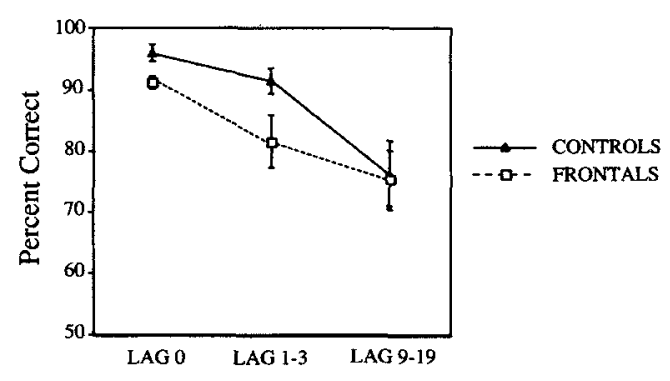

(B)

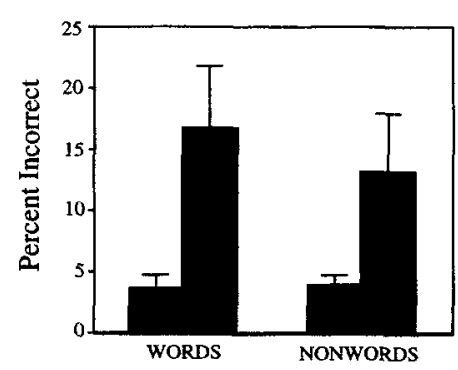

(C)

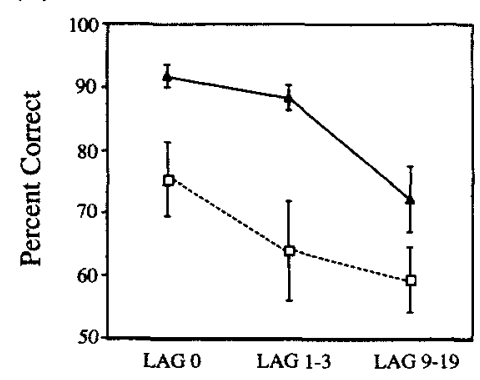

(D)

Reaction Time

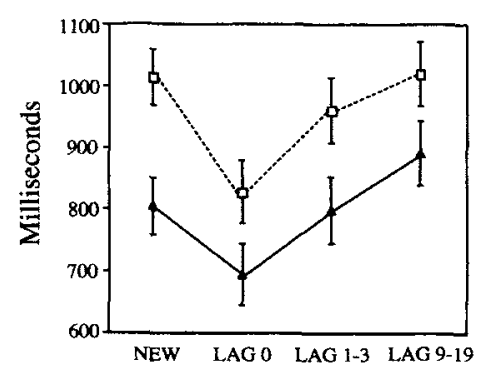

Figure 3. Behavioral performance in the continuous recognition memory task. (A) Hits are the percentage of correct responses to old words at each of the three lags. (B) False alarms are the percentage of new items incorrectly identified as old. (C) The corrected recognition measure (hits - false alarms) for words presented at each of the three lags. (D) Reaction times (in milliseconds) are illustrated for words. 
controls, $F(1,20)=4.18, p<.06$. All participants were fastest for words, $F(1,20)=26.19, p<.0001$, and for immediately repeated stimuli, with notable slowing as lag increased, $F(3,60)=58.41, p<.0001$. These main effects were modified by a Stimulus Type $\times$ Condition $\times$ Group interaction, $F(3,60)=3.34, p<.05$. In light of the different pattern of results for false alarms and hits, follow-up analyses examined RTs to new words and old words separately. Frontal patients were significantly slower in responding to new words, $F(1,20)=7.05, p<.05$, whereas their RTs to repeated words did not differ significantly from controls, $F(1,20)=2.88, p>.1$. There was no interaction between lag and group $(p>.5)$.

To summarize, the frontal patients were neither slower nor less accurate at recognizing repeated words. However, they were slower in responding to new words and were more likely to misidentify these items as old. This performance decrement is unlike what has been observed with normal aging, which is a decline in accuracy and lengthening of RTs at long delays but no change in either false-alarm rate or RTs to new stimuli (Poon \& Fozard, 1980; Friedman, Berman, \& Hamberger, 1993; Nielsen-Bohlman \& Knight, 1995; Swick \& Knight, 1997). Furthermore, the corrected recognition measure yielded significant deficits at Lag 0 and Lag 1-3 (indicative of an impairment in short-term memory) but not at Lag 9-19 (which taps long-term memory).

Given this unique pattern of results, we compared the performance of the frontal patients and controls with a group of 3 patients with hippocampal damage (see Table 1 and Figure $2 \mathrm{~B}$ for patient details). Figure 4 illustrates that the hippocampal patients showed a very low false-alarm rate and a hit rate that declined dramatically with increasing recognition delays. ${ }^{1}$ This precipitous drop was even more apparent for nonwords (Figure 4B), which was supported by the Stimulus Type $\times \mathrm{Lag} \times$ Group interaction, $F(4,44)=$ $5.23, p<.005$.

The ANOVA for false alarms yielded a marginal main effect of group, $F(2,22)=3.31, p<.06$, because of the difference between frontals and controls $(p<.05)$. The hippocampal patients did not differ from the controls $(p>.89)$ or the frontals $(p>.10)$, the latter likely because of a lack of statistical power. In contrast, post hoc tests following the main group effect for hits, $F(2,22)=13.73$, $p<.0001$, revealed that hippocampals were significantly worse than both controls $(p<.0001)$ and frontal patients $(p<.0003)$. The Lag $\times$ Group effect was also highly significant for hits, $F(4,44)=8.60, p<.0001$. Further explorations of this interaction were done by using the hits - false alarms measure. Pairwise comparisons between the controls and hippocampals found no difference at Lag 0 $(p>.16)$ but much worse performance for the patients at the longer lags $(p s<.0005)$. Pairwise comparisons between the frontals and hippocampals yielded the following: no differences at Lag $0(p>.37)$ or Lag 1-3 $(p>.73)$. However, the hippocampals were significantly less accurate than the frontals at Lag 9-19 $(p<.01)$. These findings from the continuous recognition task clearly illustrate that frontal patients do not exhibit the typical memory impairment associated with MTL damage.
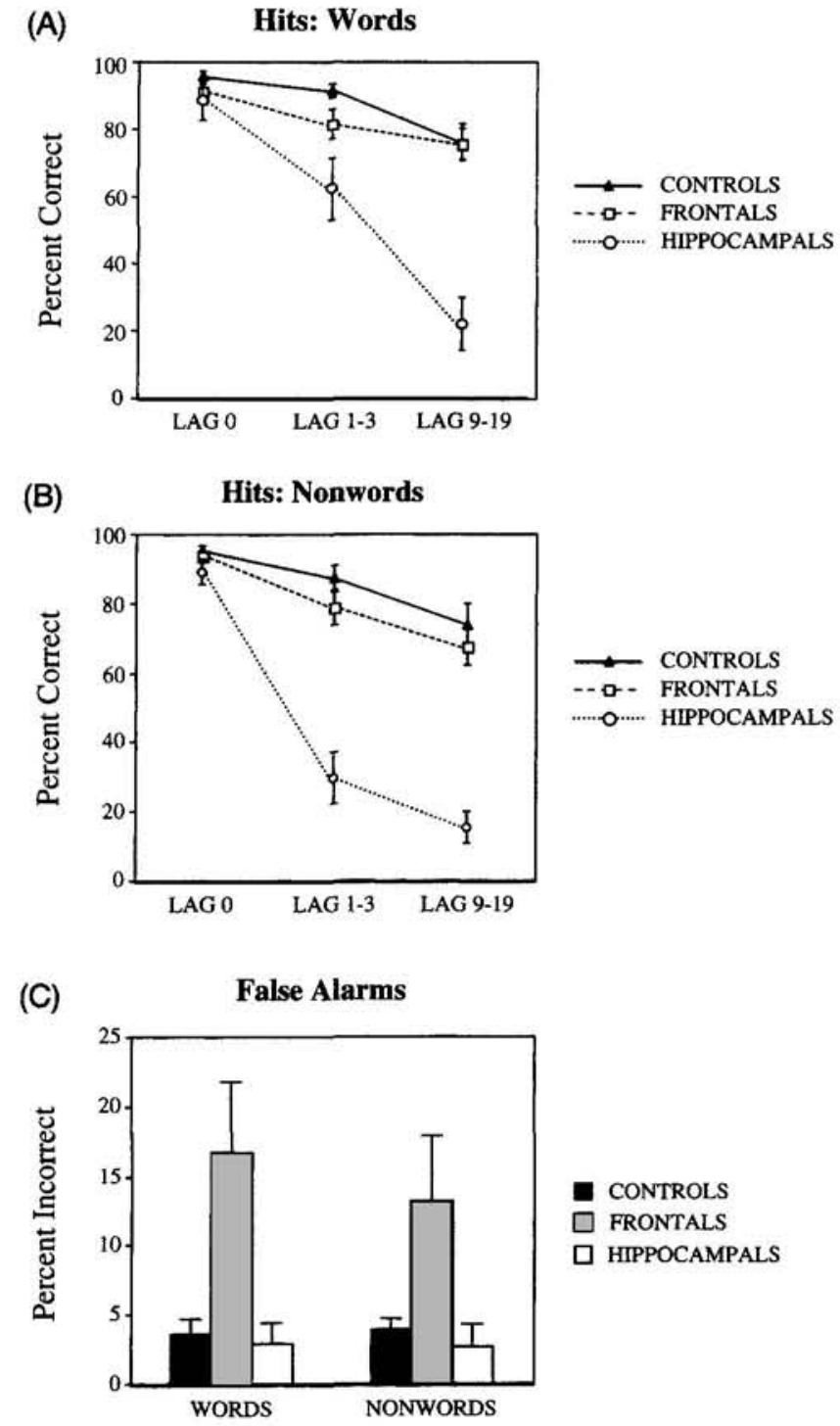

Figure 4. A comparison of (A) hits for words, (B) hits for nonwords, and (C) false alarms during recognition memory in the controls, frontal patients, and hippocampal patients.

\section{ERPs}

The first ERP components observed in the controls' waveforms included the P1 and N1 (or N170) positive and negative deflections elicited by visual stimuli. The prominent N170 component was maximal at left occipital (O1) and posterior temporal (T5) electrodes (Figure 5). N170 was significantly larger over the left hemisphere, similar to previous studies using visually presented words (Neville et al., 1986; Curran, Tucker, Kutas, \& Posner, 1993). The effects of frontal lesions on the N170 were discussed elsewhere. Briefly, frontal damage resulted in ipsilateral

\footnotetext{
${ }^{1}$ Adequate ERP averages could not be formed for the hippocampal patients because so few trials were included in the Lag 9-19 bin.
} 


\section{CONTROLS}
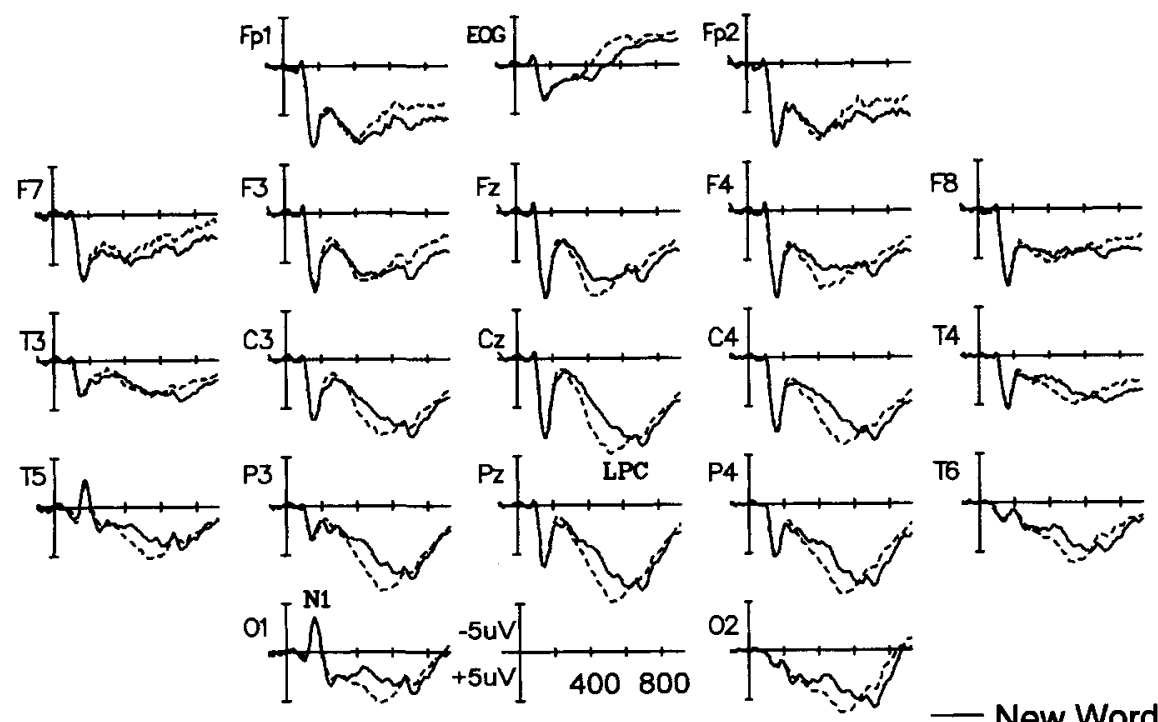

\section{- New Words \\ --- Old Words}

FRONTALS
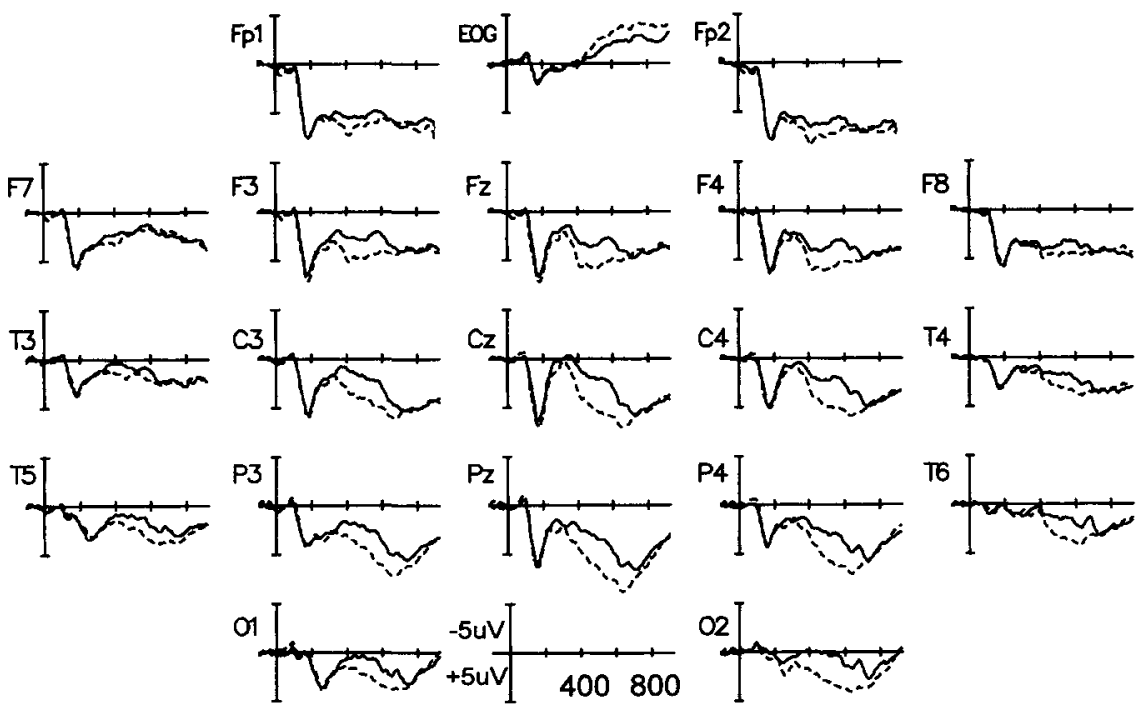

Figure 5. Grand average event-related potentials recorded from controls (top) and frontal patients (bottom) in the recognition memory task. Old words were collapsed across the three lags. The N170 (N1) and late positive component (LPC) are labeled.

reductions in N170 amplitude (Swick, 1998; Swick \& Knight, 1998).

In controls, new words elicited a late positive component (LPC), peaking at $590 \mathrm{~ms}$ and maximal at central and parietal electrodes (Figure 5). The prior N400 component, related to semantic processing and typically peaking at 400 ms (Kutas \& Van Petten, 1994), becomes difficult to identify in older adults because of its overlap with the LPC in this paradigm (Swick \& Knight, 1997). Repeated words began to diverge from new words at $300-400 \mathrm{~ms}$ with a more positive-going waveform, particularly at central and posterior sites. Large positive potentials $(400-500 \mathrm{~ms})$ were observed frontally following new words, but the effects of repetition were minimal at frontal electrodes. In the patients, the LPC evoked by new words showed a significantly later peak $(630 \mathrm{~ms})$ than in controls, $F(1,20)=4.17, p=.05$.

The mean ( \pm standard deviation) numbers of trials included in the ERP averages for controls were as follows: for new words, 156 ( \pm 18$)$; Lag 0 words, 51 ( \pm 8$)$; Lag 1-3 words, 48 ( \pm 7$)$; Lag 9-19 words, 40 ( \pm 10$)$; new nonwords, 153 ( \pm 16$)$; Lag 0 nonwords, $51( \pm 10)$; Lag 1-3 nonwords, 47 ( \pm 9$)$; and Lag 9-19 nonwords, $38( \pm 11)$. The means for frontal patients were as follows: new words, $132( \pm 36)$; Lag 0 words, 49 ( \pm 6$)$; Lag 1-3 words, 41 ( \pm 11$)$; Lag 9-19 
words, 37 ( \pm 10$)$; new nonwords, 133 ( \pm 35 ); Lag 0 nonwords, 49 ( \pm 8$)$; Lag 1-3 nonwords, 38 ( \pm 11 ); and Lag 9-19 nonwords, $30( \pm 7)$.

ERP data were initially quantified by measuring mean amplitudes within two latency windows to capture the early $(300-500 \mathrm{~ms})$ and late $(500-700 \mathrm{~ms})$ phases of the repetition effect, then entered into ANOVAs with variables of stimulus type, condition, electrode $(n=19)$, and group. For the 300-500 ms interval, repeated stimuli elicited larger positive potentials than new stimuli, $F(3,60)=9.64, p<.001$. Controls, $F(3,30)=4.24, p<.05$, and patients, $F(3,30)=$ $5.70, p<.05$, both showed a significant repetition effect. A main effect of condition was also observed for the 500 700 -ms interval, $F(3,60)=5.63, p<.005$. There were no main $(p>.1)$ or interactive $(p>.2)$ effects of group. Because the Stimulus Type $\times$ Condition interaction was not significant for either the $300-500-\mathrm{ms}(p>.5)$ or the $500-$ 700 -ms intervals $(p>.6)$, the following sections focus on ERPs to words.

Topographic differences were assessed in the normalized data set, revealing an interaction between condition and electrode, $F(54,1080)=4.64, p<.001$, that was marginally modified by group, $F(54,1080)=1.94, p<.07$. The Condition $\times$ Electrode interaction was observed for controls, $F(54,540)=5.33, p<.001$, but not for patients ( $p>.15$ ), suggesting that frontal lesions altered the scalp distribution of the repetition effect. The repetition effect was minimal over frontal regions, intermediate at occipital and posterior temporal electrodes, and largest at parietal and central sites in controls (Figure 5), whereas the effect was more equally distributed over the scalp in frontal patients. This topographic effect is explored more thoroughly in the ANOVAs for difference waves described below. For the $500-700-\mathrm{ms}$ interval, there were no main or interactive effects of group for any of the analyses.

Additional tests were run to establish the significance of any hemispheric asymmetries across conditions or groups. The 16 lateral electrodes were divided into 8 left and 8 right hemisphere leads and analyzed by five-way ANOVAs with variables of stimulus type, condition, hemisphere, electrode pair, and group. None of the ANOVAs for hemispheric asymmetries yielded any group differences, indicating that prefrontal damage did not produce a significant focal decrement in positivity.

The old-new subtraction waveforms (or difference waves) are displayed in Figure 6 and summarize the ERP repetition effect at each of the three lags. ANOVAs with variables of stimulus type, lag, electrode, and group were computed for 100 -ms intervals from 300 to $700 \mathrm{~ms}$. The normalized, mean amplitude values were used to further assess the topographic differences between controls and patients. The Electrode $\times$ Group interaction was significant for the $400-500-\mathrm{ms}$ window, $F(18,360)=2.60, p<.05$, and showed a trend for $500-600 \mathrm{~ms}, F(18,360)=2.15, p<.08$. None of the group comparisons at individual electrodes reached significance, although Fpl $(p<.1)$ and F7 $(p<.06)$ came closest because of greater positive amplitudes in the frontals. The controls tended to show greater amplitudes at some of the posterior sites (such as T5, T6, and O1), but these did not approach significance. Ironically, the ERP old-new effect showed a more frontal scalp distribution in the patients, possibly because loss of tissue beneath left frontal sites led to easier volume conduction from remote neural generators.

A final, critical set of analyses examined the reliability of the word repetition effect in controls and frontals at the parietal midline $(\mathrm{Pz})$ electrode, where it was particularly prominent. These comparisons used the old-new difference waves at each of the three lags, measured for four consecutive $100-\mathrm{ms}$ intervals (Table 2 ). These analyses confirmed that frontal lesions did not alter the magnitude of the old-new effect during recognition (Table 2 and Figure 7). In fact, the patients generated a larger repetition effect than controls in the 600-700-ms window, $F(1,20)=4.87, p<$ .05 , indicative of its longer duration in the frontal group. The main effect of lag was evident in the 400-500-ms window, $F(2,40)=51.73, p<.002$, indicating that the amplitude of the ERP old-new effect declined with increasing retention interval. The Lag $\times$ Group interaction was not significant for any latency window $(p s>.38)$.

\section{Discussion}

PET studies have initiated an increased interest in the role of prefrontal cortex in memory (Andreasen et al., 1995; Buckner et al., 1995; Buckner, Raichle, Miezin, \& Petersen, 1996; Grasby et al., 1993; Petrides, Alivisatos, \& Evans, 1995; Squire et al., 1992; Tulving, Kapur, Craik, Moscovitch, \& Houle, 1994; Tulving, Kapur, Markowitsch, et al., 1994). However, patients with frontal lesions do not show the classic episodic memory deficits associated with amnesia (Shimamura, 1995) and instead show problems with attention and sensory gating (Knight, Hillyard, Woods, \& Neville, 1981; Knight, Scabini, \& Woods, 1989; Woods \& Knight, 1986) that can result in inefficient use of strategies, distractibility, and interference effects (Shallice \& Burgess, 1991; Shimamura, Jurica, Mangels, Gershberg, \& Knight, 1995; reviewed in Swick \& Knight, 1998). Below, we discuss how the present experiment may help to elucidate the contributions of prefrontal cortex to episodic memory and relate these findings to the neuroimaging literature.

\section{Recognition and Prefrontal Cortex}

The behavioral consequences of prefrontal lesions were very different from what is observed with normal aging (Swick \& Knight, 1997) and with unilateral hippocampal lesions. Namely, there was a double dissociation for hits and false alarms in the frontal and hippocampal patients using the continuous recognition procedure. The frontal patients showed an elevated false-alarm rate and a hit rate comparable to controls, whereas the hippocampal patients showed a normal false-alarm rate and a hit rate that declined disproportionately at the longest retention interval. This orthogonal pattern of results in the two groups provides further support for the argument that frontals do not show a simple memory deficit but rather impairments in their use of strategies (Gershberg \& Shimamura, 1995), source monitor- 

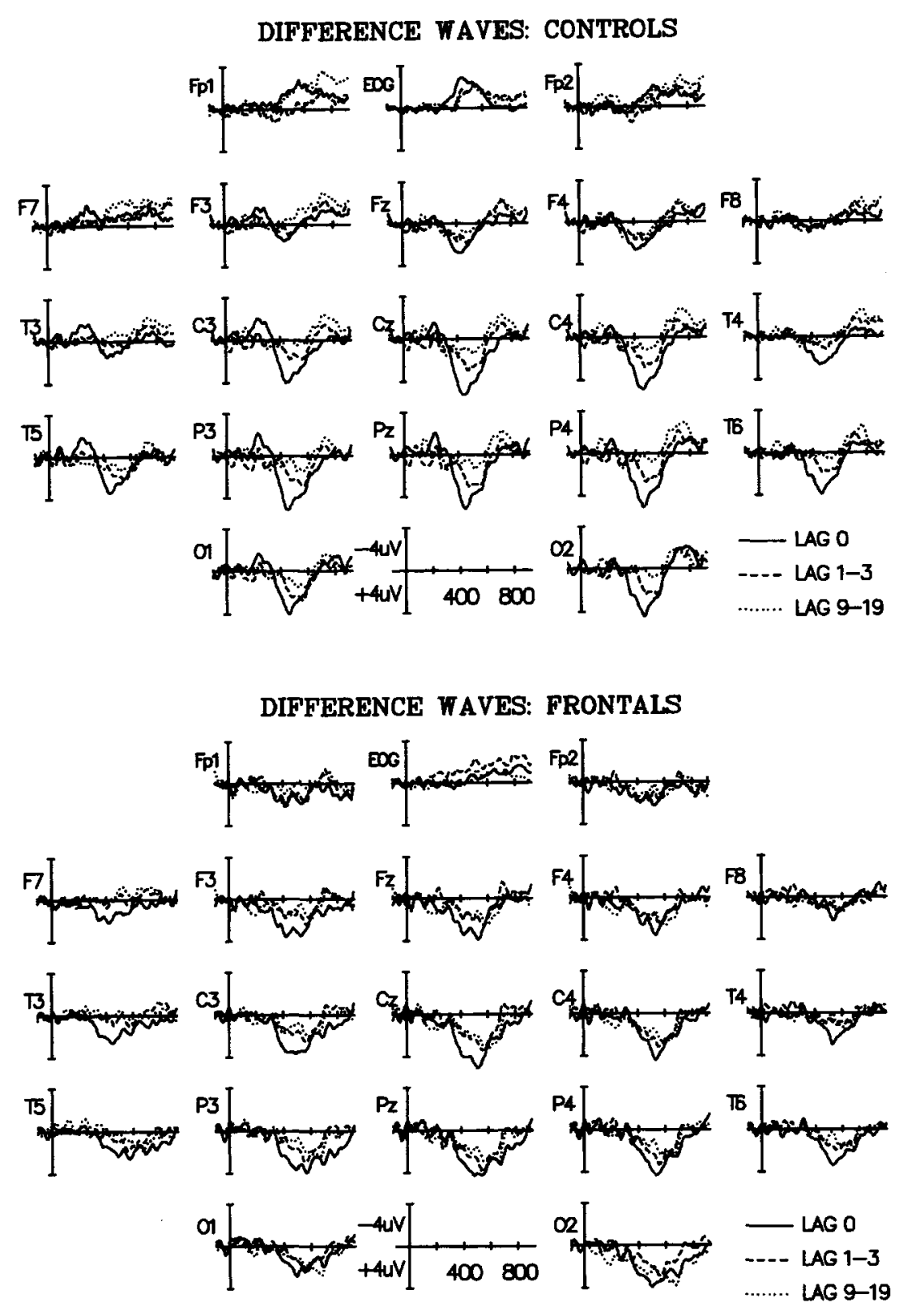

Figure 6. Difference waveforms (old words - new words) at each of the three lags plotted separately for controls (top) and frontal patients (bottom).

ing (M. K. Johnson, Hashtroudi, \& Lindsay, 1993), and working-with-memory processes (Moscovitch, 1994). Furthermore, the hippocampal patients were much less accurate than the frontal patients at the longest lag, even after correction for the latter's liberal response bias.

Elevated false-alarm rates have been previously reported in frontal patients. A patient with right frontal damage (patient B.G.) committed more false alarms in a series of recognition experiments (Curran, Schacter, Norman, \& Galluccio, 1997; Schacter, Curran, Galluccio, Milberg, \& Bates, 1996). This deficit was eliminated by the use of a semantic study task (Curran et al., 1997) and the use of categorized lists and presentation of test items from nonstud- ied categories (Schacter, Curran, et al., 1996). High falsealarm rates and false recognition have also been observed in patients with ruptured anterior communicating artery aneurysms (Parkin, Bindschaedler, Harsent, \& Metzler, 1996; Rapcsak et al., 1998). However, these patients have very different regions of frontal lobe damage (e.g., ventromedial frontal, orbital frontal, anterior cingulate, and basal forebrain) than the dorsolateral prefrontal lesions in our patients and patient B.G., and they often engage in spontaneous confabulation (Rapcsak et al., 1998), also unlike our patients and B.G. Additional studies with larger groups of patients can help to ascertain whether different frontal lobe subdivisions make separable contributions to strategic types of 
Table 2

Mean Amplitudes and Standard Deviations of the Repetition Effect (Old-New Difference Waves in $\mu \mathrm{V}$ ) at 100-ms Intervals, Recorded From the Parietal Midline Electrode in the Recognition Memory Task

\begin{tabular}{|c|c|c|c|c|c|c|c|c|}
\hline \multirow{3}{*}{$\begin{array}{l}\text { Group } \\
\text { and lag }\end{array}$} & \multicolumn{8}{|c|}{ Interval (ms) } \\
\hline & \multicolumn{2}{|c|}{$300-400$} & \multicolumn{2}{|c|}{$400-500$} & \multicolumn{2}{|c|}{$500-600$} & \multicolumn{2}{|c|}{$600-700$} \\
\hline & $M$ & $S D$ & $M$ & $S D$ & $M$ & $S D$ & $M$ & $S D$ \\
\hline \multicolumn{9}{|l|}{ Controls } \\
\hline Lag 0 & 1.12 & 3.94 & 4.39 & $3.52 * *$ & 3.14 & $3.83^{*}$ & 0.64 & 4.82 \\
\hline Lag 1-3 & 0.89 & 1.69 & 2.25 & $2.34 * *$ & 2.84 & $2.03 * * *$ & 0.21 & 4.22 \\
\hline Lag 9-19 & 0.24 & 2.12 & 0.46 & 3.70 & 0.75 & 3.50 & -1.10 & 2.62 \\
\hline \multicolumn{9}{|l|}{ Frontals } \\
\hline Lag 0 & 1.26 & 2.28 & 3.60 & $2.40 * * *$ & 3.94 & $2.92 * *$ & 2.85 & $2.61^{* *}$ \\
\hline Lag 1-3 & 0.56 & 2.07 & 1.79 & $2.44 *$ & 3.32 & $2.33 * * *$ & 2.23 & $2.38^{*}$ \\
\hline Lag 9-19 & 0.82 & 2.44 & 1.48 & 2.86 & 2.24 & $3.16^{*}$ & 2.75 & 4.39 \\
\hline
\end{tabular}

Note. The changes in voltage elicited by repeated words in each condition were analyzed using one-sample $t$ tests.

${ }^{*} p<.05 . \quad * * p<.01 . \quad * * * p<.001$.

encoding, retrieval, monitoring, and criterion-setting or decision-making processes during memory tests.

Frontal patients generally show disproportionate deficits in free recall with relatively intact recognition (Janowsky, Shimamura, Kritchevsky, et al., 1989), but Stuss et al. (1994) reported mild recognition deficits in left frontal patients that correlated with the degree of anomia (as measured by the Boston Naming Test; Kaplan, Goodglass, $\&$ Weintraub, 1983). Stuss et al. suggested that less elaborated verbal encoding might have been responsible for the impairments in these patients. In the current experiment, however, a comparison of the overall recognition accuracy of the 5 most aphasic frontal patients with that of the 6 others (4 nonaphasic, 2 mild anomia) did not yield an overall difference between these frontal subgroups, $F(1,9)=0.17$, $p>$.69. Likewise, the cued recall performance of anomic aphasic patients with damage to left inferior prefrontal cortex and nonaphasic left superior prefrontal patients did not differ (Swick \& Knight, 1996). These discrepancies could be due to variations in experimental paradigms, patient-selection criteria, and time postinjury.

In contrast to the frontal patients, the hippocampal patients did not commit more false alarms than controls but rather showed a steep decline in hit rates with increasing retention interval. Previous results from our group (Kroll,
Knight, Metcalfe, Wolf, \& Tulving, 1996) also demonstrated that unilateral hippocampal patients $(n=15)$ did not make more false alarms to new words presented in a continuous recognition paradigm. Instead, patients with left hippocampal damage made more conjunction errors to words that combined syllables from two previously presented words.

Moscovitch (1994) has proposed a neuropsychological model of memory that consists of four components. Of most relevance here is the comparison between the MTL memory system that mediates encoding, storage, and retrieval on explicit tests and the prefrontal working-with-memory system that mediates strategic memory performance. The latter rubric includes monitoring the output of the memory system in order to set an appropriate criterion for judging items as familiar. If false alarms are viewed as misattributions of familiarity (Jacoby, Toth, \& Yonelinas, 1993) rather than faulty recollective processes, then lateral prefrontal cortex may play a greater role in familiarity than in recollection during recognition tests. This proposal is consistent with the finding of an intact ERP old-new effect in the patients.

The hemispheric encoding-retrieval asymmetry model was proposed to account for the pattern of blood flow changes in PET studies of episodic memory (Tulving, Kapur, Craik, et al., 1994); namely that left prefrontal cortex is preferentially activated during encoding, whereas right
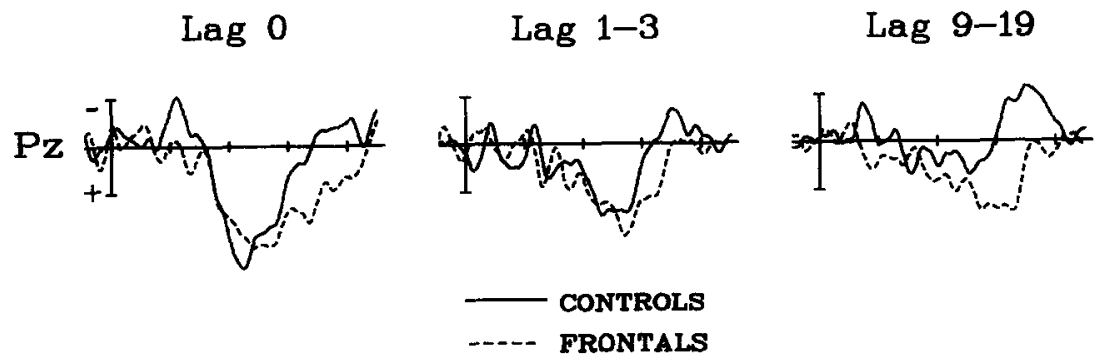

Figure 7. Difference waveforms (old words - new words) at each of the three lags, recorded from the midline parietal electrode in controls compared with frontal patients. Stimulus onset is indicated by the vertical calibration bar, which is $\pm 2 \mu \mathrm{V}$. Negative is up, and tick marks are $200 \mathrm{~ms}$. 
prefrontal cortex is more involved in retrieval. This model predicts that either left or right prefrontal damage should produce memory impairments. The left posterior prefrontal regions damaged in the majority of patients have been implicated in PET studies of verbal memory, primarily retrieval from semantic memory and encoding into episodic memory, but activations of left prefrontal cortex have also been observed during retrieval from episodic memory (Backman, et al., 1997; Buckner et al., 1995, 1996; Cabeza et al., 1997; Kapur et al., 1995; Schacter, Alpert, et al., 1996; Schacter, Savage, Alpert, Rauch, \& Albert, 1996). In the current study, left frontal patients did not show a simple encoding deficit because their corrected recognition scores did not show a disproportionate drop at the longest delay, as was observed in the hippocampal patients. In fact, relatively greater impairments were seen at short lags, which is more suggestive of a problem with rapid working memory circuits. The lack of right frontal patients in the current study ${ }^{2}$ does not allow us to draw strong conclusions about right prefrontal cortex and retrieval, but prior behavioral results demonstrated that right prefrontal patients were not impaired in word stem cued recall (Swick \& Knight, 1996).

We should also note that recognition places lighter demands on retrieval processes than either cued recall or free recall. However, the continuous recognition procedure may tap strategic processing to a greater extent than a study-test paradigm because participants must switch between identifying and encoding new stimuli and recognizing old stimuli, which may be more difficult for the frontal patients. Encoding in this paradigm is not constrained by task requirements for the initial study episode to be deep or shallow. We also suggest that the higher error rates and longer RT's for new words could reflect a defect in novelty detection, rather than a deficiency in encoding per se. Patients with dorsolateral prefrontal lesions show a reduction in the P3a component, an ERP orienting response to novel stimuli (Knight, 1984). Along these lines, we did a direct group comparison of the ERPs to new words. ANOVAs were performed for mean amplitudes within four 100 -ms windows from 300 to $700 \mathrm{~ms}$. Frontal patients generated significantly less positivity from 500 to $600 \mathrm{~ms}$, $F(1,20)=7.97, p<.02$. Strategic processing, novelty detection, and working memory all contribute to episodic memory performance, and we suggest that lateral prefrontal cortex is preferentially involved in these processes, whereas the MTL region is more essential for encoding.

However, the novelty of nonwords was helpful to the frontal patients because their false-alarm rate to new nonwords was lower. The higher false-alarm rate for words compared with nonwords suggests a problem with context. The frontals have a greater problem rejecting new words because they have the potential of being familiar. Their criterion-setting, decision-making, and working-withmemory systems have a more difficult time with new words because they are more likely to resemble previously presented, more familiar items and cause interference. The present ERP results are particularly illuminating regarding the types of memory processes that are intact in the frontal patients. As discussed below, the ERPs are a closer reflection of memory success in the frontals than memory failure.

\section{Memory-Related ERPs and Prefrontal Cortex}

The major electrophysiological finding of the present experiment was that the amplitude of the ERP old-new effect was not diminished by lesions centered in the posterior regions of left dorsolateral prefrontal cortex. The ERP old-new effect was manifest as a positive deflection in the waveform to correctly recognized old words relative to new words from approximately 400 to $700 \mathrm{~ms}$ poststimulus. Prior studies have shown that ERP repetition effects in elderly individuals are preserved in implicit memory tasks and at short recognition delays but are abolished for recognition at long delays (Rugg, Mark, Gilchrist, \& Roberts, 1997; Swick \& Knight, 1997). The present experiment also observed reductions in the ERP effect and accuracy at the longest lag in older controls. However, the old-new ERP effect was intact in the frontal patients. In comparison with controls, frontal patients showed neither a decrease in the size or duration of the ERP repetition effect nor a delay in its onset during recognition. Because the onset of the old-new effect occurs several hundred milliseconds prior to RTs for correctly recognized words, left prefrontal cortex is not necessary for the ERP modulation associated with successful recognition. ${ }^{3}$

We further suggest that the hit rate in the frontal patients reflected normal memory for old items and not inflation due to bias because their ERP repetition effect was intact. When they responded correctly to old words, the magnitude of the effect in the patients did not differ from controls. Inflation due to bias would be likely to dilute the ERP old-new effect.

\footnotetext{
${ }^{2}$ The inclusion criterion for etiology of frontal lesion in the present study was limited to stroke. Patients with resected tumors and craniotomies for trauma were excluded because of two problems: (a) EEG currents may be shunted through postcraniotomy skull defects, producing distortions in ERP amplitudes and scalp topographies and (b) chronic EEG slowing may persist over resected tumors and alter the signal-noise ratios of ERPs. Patients with isolated left frontal strokes typically present more often in the clinic (because of their language disorders) than those with right frontal strokes.

${ }^{3}$ One interesting (although unreported) aspect of the present data was the ERPs to false alarms. Which did they resemble more: ERPs to hits or correct rejections? It was not at all the case that they resembled ERPs to hits (see also Van Petten \& Senkfor, 1996), implying that neither the frontals nor the controls exhibited false recognition. A trend that was examined in the data was whether false-alarm ERPs to words resembled the ERPs for correctly identified new words in frontals but not controls. Perhaps the frontals recognized many of these stimuli as new but their faulty monitoring (M. K. Johnson et al., 1993) or working-with-memory processes (Moscovitch, 1994) led to the higher false alarm rate. Unfortunately, these data were impossible to quantify because 4 patients had too few false-alarm trials (fewer than 10) to form a clean average. This was even more true for the controls (the mean number of false-alarm trials was 6); therefore, these data could not be reported. They must remain as preliminary qualitative observations until further experiments are performed.
} 
This did not occur. If the ERP old-new effect observed during explicit memory tasks reflects recollection to a greater extent than familiarity (Düzel et al., 1997; Smith, 1993), then trials associated with lucky guesses (because of the liberal response bias) would not contribute to the ERP old-new effect at all. Hence, its strength would have been weaker.

In fact, the ERP old-new effect of the frontal patients was actually larger than that of the controls for the $600-700-\mathrm{ms}$ interval. The role of confidence may be helpful in explaining why the frontals had a greater ERP old-new effect at longer delays. Recent evidence suggests that confidence affects the size of the ERP response to hits and, to a lesser extent, the size of the LPC to correct rejections (Rubin, Van Petten, Glisky, \& Newberg, in press). It could be that the frontals actually gave more confident responses for hits than did the age-matched (mostly elderly) controls.

What do the ERP findings reveal about memory processes that are intact in the frontal patients? The ERPs go beyond the behavioral data to suggest that recollection itself is unaffected by left lateral prefrontal lesions. We maintain that our reported ERP old-new effect probably reflects memory processes that are nonstrategic, both short-term and longterm in nature, and more closely associated with recollection than familiarity. The tentative conclusion that the neurophysiological substrates of recollection were unaltered in the frontal patients awaits confirmation from ERP experiments that apply the Remember-Know procedure.

The strategic memory failure in the frontals was not clearly reflected in the ERPs. For the frontal patients, strategy was more an issue for new words than old words because of what their strategy actually was. Their strategy was a bias to say "Yes, I've seen it before." This bias did inflate their hit rate, but even when corrected, hit rate did not show a disproportionate decline with increasing delay. Even at long delays, correct recognition was associated with an ERP old-new effect in the frontals. In addition to the higher false-alarm rate, the slower RTs and smaller LPC for new items could be consistent with a deficit in postretrieval monitoring or checking. Conversely, the strategy of the hippocampal patients was to say "No, I haven't seen it before" if the item did not look familiar to them. We refer to it as a strategy because one might expect something closer to a 50\% hit rate for Lag 9-19 items and a much higher false alarm rate if they had been merely guessing.

Prefrontal activations measured with PET may reflect retrieval attempt (Kapur et al., 1995; Schacter, Alpert, et al., 1996) or postretrieval evaluative processes (Rugg et al., 1996), but this activity may not be essential for retrieval success. A recent functional magnetic resonance imaging study of verbal recognition used an averaged single-trial design and found that signal onset in anterior prefrontal cortex was delayed approximately $2-4 \mathrm{~s}$, relative to other activations (Schacter, Buckner, Koutstaal, Dale, \& Rosen, 1997). Hence, prefrontal hemodynamic changes may not reflect neural activity that precedes recognition judgments. We predict that ERP fluctuations associated with retrieval of study context, such as modality (Wilding, Doyle, \& Rugg, 1995), voice (Senkfor \& Van Petten, 1998; Wilding \& Rugg,
1996), and temporal order (Trott, Friedman, Ritter, \& Fabiani, 1997), will require prefrontal cortex. ${ }^{4}$

Additionally, the preservation of the ERP memory-related response suggests that neural generators in medial temporal regions and posterior association cortex (Halgren, Baudena, Heit, Clark, \& Marinkovic, 1994) are responsible for modulating these potentials during an explicit memory condition. For example, anterior temporal lobectomy reduces the ERP repetition effect during recognition (Rugg et al., 1991; Smith \& Halgren, 1989). Depth recordings in the MTL have revealed potentials resembling the scalp $\mathrm{N} 400$ and LPC (Guillem et al., 1995; Puce, Andrewes, Berkovic, \& Bladin, 1991; Smith, Stapleton, \& Halgren, 1986). An extensive intracranial sampling of limbic and posterior cortical regions found local sources of the word repetition effect in the hippocampus, rhinal cortex, lingual and fusiform gyri, superior and middle temporal gyri, and lateral occipitotemporal cortex (Halgren, Baudena, Heit, Clark, \& Marinkovic, 1994). However, focal, polarity-inverting potentials related to the scalp N400 and LPC have been recorded from intracranial electrodes placed in Broca's area and lateral orbitofrontal cortex, with larger amplitudes in the latter (Guillem et al., 1995; Halgren, Baudena, Heit, Clark, Marinkovic, \& Chauvel, 1994). In the study of Halgren, Baudena, Heit, Clark, Marinkovic, and Chauvel (1994), ERPs at the frontal contacts were not highly sensitive to word repetition, which agrees with the preservation of the ERP old-new effect in the present lesion data.

Because most PET experiments are done with young adults, a final comment concerns the changes observed with aging. Some of the discrepancies between the PET and neuropsychological literatures may be narrowed with additional neuroimaging studies of memory in older adults, which have already shown alterations in frontal activity with aging (Grady et al., 1995; Schacter, Savage, et al. 1996; Cabeza et al., 1997). However, the frontal patients exhibited a different pattern of results from what has been reported in the normal aging literature, which argues against the idea that recognition deficits in elderly individuals are solely due to frontal lobe degeneration.

${ }^{4}$ This point indirectly raises the contentious issue of whether source memory is an essential component of subjective recollective experience (Yonelinas \& Jacoby, 1995) or not (Gardiner \& Java, 1993). Although we have implied that it is not, we do not wish to enter this debate at the moment.

\section{References}

Allan, K., \& Rugg, M. D. (1997). An event-related potential study of explicit memory on tests of cued recall and recognition. Neuropsychologia, 35, 387-397.

Andreasen, N. C., O'Leary, D. S., Arndt, S., Cizadlo, T., Hurtig, R., Rezai, K., Watkins, G. L., Ponto, L. L. B., \& Hichwa, R. D. (1995). Short-term and long-term verbal memory: A positron emission tomography study. Proceedings of the National Academy of Science, 92, 5111-5115.

Backman, L., Almkvist, O., Andersson, J., Nordberg, A., Winblad, B., Reineck, R., \& Langstrom, B. (1997). Brain activation in 
young and older adults during implicit and explicit retrieval. Journal of Cognitive Neuroscience, 9, 378-391.

Buckner, R. L. (1996). Beyond HERA: Contributions of specific prefrontal brain areas to long-term memory retrieval. Psychonomic Bulletin and Review, 3, 149-158.

Buckner, R. L., Petersen, S. E., Ojemann, J. G., Miesin, F. M., Squire, L. R., \& Raichle, M. E. (1995). Functional anatomical studies of explicit and implicit memory retrieval tasks. Journal of Neuroscience, 15, 12-29.

Buckner, R. L., Raichle, M. E., Miezin, F. M., \& Petersen, S. E. (1996). Functional anatomic studies of memory retrieval for auditory words and visual pictures. Journal of Neuroscience, 16 , 6219-6235.

Cabeza, R., Grady, C. L., Nyberg, L., McIntosh, A. R., Tulving, E., Kapur, S., Jennings, J. M., Houle, S., \& Craik, F. I. M. (1997). Age-related differences in neural activity during memory encoding and retrieval: A positron emission tomography study. Journal of Neuroscience, 17, 391-400.

Curran, T., Schacter, D. L., Norman, K. A., \& Galluccio, L. (1997). False recognition after a right frontal lobe infarction: Memory for general and specific information. Neuropsychologia, 35, 1035-1049.

Curran, T., Tucker, D. M., Kutas, M., \& Posner, M. I. (1993). Topography of the $\mathrm{N} 400$ : Brain electrical activity reflecting semantic expectancy. Electroencephalography and Clinical Neurophysiology, 88, 188-209.

Demb, J. B., Desmond, J. E., Wagner, A. D., Vaidya, C. J., Glover, G. H., \& Gabrieli, J. D. E. (1995). Semantic encoding and retrieval in the left inferior prefrontal cortex: A functional MRI study of task difficulty and process specificity. Journal of Neuroscience, 15, 5870-5878.

Düzel, E., Yonelinas, A. P., Mangun, G. R., Heinze, H.-J., \& Tulving, E. (1997). Event-related brain potential correlates of two states of conscious awareness in memory. Proceedings of the National Academy of Science, 94, 5973-5978.

Francis, W. N., \& Kucera, H. (1982). Frequency analysis of English usage: Lexicon and grammar. Boston: Houghton Mifflin.

Friedman, D. (1990). ERPs during continuous recognition memory for words. Biological Psychology, 30, 61-87.

Friedman, D., Berman, S., \& Hamberger, M. (1993). Recognition memory and ERPs: Age-related changes in young, middle-aged, and elderly adults. Journal of Psychophysiology, 7, 181-201.

Gardiner, J. M., \& Java, R. I. (1993). Recognizing and remembering. In A. F. Collins, S. E. Gathercole, M. A. Conway, \& P. E. Morris (Eds.), Theories of memory (pp. 163-188). Hillsdale, NJ: Erlbaum.

Gershberg, F. B., \& Shimamura, A. P. (1995). Impaired use of organizational strategies in free recall following frontal lobe damage. Neuropsychologia, 33, 1305-1333.

Grady, C. L., McIntosh, A. R., Horwitz, B., Maisog, J. M., Ungerleider, L. G., Mentis, M. J., Pietrini, P., Schapiro, M. B., \& Haxby, J. V. (1995). Age-related reductions in human recognition memory due to impaired encoding. Science, 269, 218-221.

Grasby, P. M., Frith, C. D., Friston, K. J., Bench, C., Frackowiak, R. S. J., \& Dolan, R. J. (1993). Functional mapping of brain areas implicated in auditory-verbal memory function. Brain, 116 , $1-20$.

Guillem, F., N'Kaoua, B., Rougier, A., \& Claverie, B. (1995). Intracranial topography of event-related potentials (N400/P600) elicited during a continuous recognition memory task. Psychophysiology, 32, 382-392.

Haist, F., Shimamura, A. P., \& Squire, L. R. (1992). On the relationship between recall and recognition memory. Journal of Experimental Psychology: Learning, Memory, and Cognition, $20,130-149$.
Halgren, E., Baudena, P., Heit, G., Clark, J. M., \& Marinkovic, K. (1994). Spatio-temporal stages in face and word processing. 1. Depth-recorded potentials in the human occipital, temporal, and parietal lobes. Journal of Physiology, 88, 1-50.

Halgren, E., Baudena, P., Heit, G., Clark, J. M., Marinkovic, K., \& Chauvel, P. (1994). Spatio-temporal stages in face and word processing. 2. Depth-recorded potentials in the human frontal and Rolandic cortices. Journal of Physiology, 88, 51-80.

Halgren, E., Marinkovic, K., \& Chauvel, P. (1998). Generators of the late cognitive potentials in auditory and visual oddball tasks. Electroencephalography and Clinical Neurophysiology, 106, 156-164.

Hillyard, S. A., \& Picton, T. W. (1987). Electrophysiology of cognition. In F. Plum (Ed.), Handbook of physiology: The nervous system (Vol. V, pp. 519-584). Bethesda, MD: American Physiological Society.

Incisa della Rocchetta, A., \& Milner, B. (1993). Strategic search and retrieval inhibition: The role of the frontal lobes. Neuropsychologia, 33, 503-524.

Jacoby, J. J., Toth, J. P., \& Yonelinas, A. P. (1993). Separating conscious and unconscious influences of memory: Measuring recollection. Journal of Experimental Psychology: General, 122, 139-154.

Janowsky, J. S., Shimamura, A. P., Kritchevsky, M., \& Squire, L. R. (1989). Cognitive impairment following frontal lobe damage and its relevance to human amnesia. Behavioral Neuroscience, $103,548-560$.

Janowsky, J. S., Shimamura, A. P., \& Squire, L. R. (1989). Source memory impairment in patients with frontal lobe lesions. Neuropsychologia, 27, 1043-1056.

Jetter, W., Poser, U., Freeman, R. B., \& Markowitsch, H. J. (1986). A verbal long term memory deficit in frontal lobe damaged patients. Cortex, 22, 229-242.

Johnson, M. K., Hashtroudi, S., \& Lindsay, D. S. (1993). Source monitoring. Psychological Bulletin, 114, 3-28.

Johnson, R., Jr. (1995). On the neural generators of the P300: Evidence from temporal lobectomy patients. In G. Karmos, M. Molner, V. Csepe, \& I. Czigler (Eds.), Perspectives of eventrelated potential research (EEG Suppl. 44, pp. 110-129). Amsterdam: Elsevier.

Kaplan, E. F., Goodglass, H., \& Weintraub, S. (1983). The Boston Naming Test (2nd ed.). Philadelphia: Lea \& Febiger.

Kapur, S., Craik, F. I. M., Jones, C., Brown, G. M., Houle, S., \& Tulving, E. (1995). Functional role of the prefrontal cortex in retrieval of memories: A PET study. NeuroReport, 6, 1880-1884.

Kapur, S., Craik, F. I. M., Tulving, E., Wilson, A. A., Houle, S., \& Brown, G. M. (1994). Neuroanatomical correlates of encoding in episodic memory: Levels of processing effect. Proceedings of the National Academy of Science, 91, 2008-2011.

Kertesz, A. (1982). Western Aphasia Battery. New York: Grune \& Stratton.

Knight, R. T. (1984). Decreased response to novel stimuli after prefrontal lesions in man. Electroencephalography and Clinical Neurophysiology, 59, 9-20.

Knight, R. T., Hillyard, S. A., Woods, D. L., \& Neville, H. J. (1981). The effects of frontal cortex lesions on event-related potentials during auditory selective attention. Electroencephalography and Clinical Neurophysiology, 52, 571-582.

Knight, R. T., Scabini, D., \& Woods, D. L. (1989). Prefrontal cortex gating of auditory transmission in humans. Brain Research, 504, 338-342.

Koles, Z. J. (1998). Trends in EEG source localization. Electroencephalography and Clinical Neurophysiology, 106, 127-137. 
Kroll, N. E. A., Knight, R. T., Metcalfe, J., Wolf, E. S., \& Tulving, E. (1996). Cohesion failure as a source of memory illusions. Journal of Memory and Language, 35, 176-196.

Kutas, M., \& Van Petten, C. (1994). Psycholinguistics electrified: Event-related brain potential investigations. In M. Gernsbacher (Ed.), Handbook of psycholinguistics (pp. 83-143). New York: Academic Press.

Luria, A. R. (1966). Higher cortical functions in man. New York: Basic Books.

Mangels, J. A. (1997). Strategic processing and memory for temporal order in patients with frontal lobe lesions. Neuropsychology, 11, 207-221.

McAndrews, M. P., \& Milner, B. (1991). The frontal cortex and memory for temporal order. Neuropsychologia, 29, 849-859.

McCarthy, G., \& Wood, C. C. (1985). Scalp distributions of event-related potentials: An ambiguity associated with analysis of variance models. Electroencephalography and Clinical Neurophysiology, 62, 203-208.

Milner, B. (1964). Some effects of frontal lobectomy in man. In J. M. Warren \& K. Akert (Eds.), The frontal granular cortex and behavior (pp. 313-334). New York: McGraw-Hill.

Moscovitch, M. (1994). Memory and working with memory: Evaluation of a component process model and comparisons with other models. In D. L. Schacter \& E. Tulving (Eds.), Memory systems 1994 (pp. 269-310). Cambridge, MA: MIT Press.

Neville, H., Kutas, M., Chesney, G., \& Schmidt, A. (1986). Event-related brain potentials during initial encoding and recognition memory of congruous and incongruous words. Journal of Memory and Language, 25, 75-92.

Nielsen-Bohlman, L., \& Knight, R. T. (1995). Prefrontal alterations during memory processing in aging. Cerebral Cortex, 5, 541549 .

Nyberg, L., Cabeza, R., \& Tulving, E. (1996). PET studies of encoding and retrieval: The HERA model. Psychonomic Bulletin and Review, 3, 135-148.

Nyberg, L., Tulving, E., Habib, R., Nilsson, L.-G., Kapur, S., Houle, S., Cabeza, R., \& McIntosh, A. R. (1995). Functional brain maps of retrieval mode and recovery of episodic information. NeuroReport, 7, 249-252.

Paller, K. A., \& Kutas, M. (1992). Brain potentials during memory retrieval provide neurophysiological support for the distinction between conscious recollection and priming. Journal of Cognitive Neuroscience, 4, 375-391.

Parkin, A. J., Bindschaedler, C., Harsent, L., \& Metzler, C. (1996). Pathological false alarm rates following damage to the left frontal cortex. Brain and Cognition, 32, 14-27.

Petrides, M., Alivisatos, B., \& Evans, A. C. (1995). Functional activation of the human ventrolateral frontal cortex during mnemonic retrieval of verbal information. Proceedings of the National Academy of Science, 92, 5803-5807.

Petrides, M., \& Milner, B. (1982). Deficits on subject-ordered tasks after frontal- and temporal-lobe lesions in man. Neuropsychologia, 20, 249-262.

Poon, L. W., \& Fozard, J. L. (1980). Age and word frequency effects in continuous recognition memory. Journal of Gerontology, 35, 77-86.

Puce, A., Andrewes, D. G., Berkovic, S. F., \& Bladin, P. F. (1991). Visual recognition memory: Neurophysiological evidence for the role of temporal white matter in man. Brain, 114, 1647-1666.

Rapcsak, S. Z., Kaszniak, A. W., Reminger, S. L., Glisky, M. L., Glisky, E. L., \& Comer, J. F. (1998). Dissociation between verbal and autonomic measures of memory following frontal lobe damage. Neurology, 50, 1259-1265.

Rubin, S. R., Van Petten, C., Glisky, E. L., \& Newberg, W. M. (in press). Memory conjunction errors in younger and older adults:
Event-related potential and neuropsychological data. Journal of Memory and Language.

Rugg, M. D. (1995). Event-related potential studies of human memory. In M. S. Gazzaniga (Ed.), The cognitive neurosciences (pp. 789-813). Cambridge, MA: MIT Press.

Rugg, M. D., \& Doyle, M. C. (1992). Event-related potentials and recognition memory for low- and high-frequency words. Journal of Cognitive Neuroscience, 4, 69-79.

Rugg, M. D., Fletcher, P. C., Frith, C. D., Frackowiak, R. S. J., \& Dolan, R. J. (1996). Differential activation of the prefrontal cortex in successful and unsuccessful memory retrieval. Brain, 119, 2073-2083.

Rugg, M. D., Mark, R. E., Gilchrist, J., \& Roberts, R. C. (1997). ERP repetition effects in indirect and direct tasks: Effects of age and inter-item lag. Psychophysiology, 34, 572-586.

Rugg, M. D., \& Nagy, M. E. (1989). Event-related potentials and recognition memory for words. Electroencephalography and Clinical Neurophysiology, 72, 395-406.

Rugg, M. D., Roberts, R. C., Potter, D. D., Pickles, C. D., \& Nagy, M. E. (1991). Event-related potentials related to recognition memory: Effects of unilateral temporal lobectomy and temporal lobe epilepsy. Brain, 114, 2313-2332.

Sagar, H. J., Sullivan, E. V., Gabrieli, J. D. E., Corkin, S., \& Growdon, J. H. (1988). Temporal ordering and short-term memory deficits in Parkinson's disease. Brain, 111, 525-539.

Schacter, D. L., Alpert, N. M., Savage, C. R., Rauch, S. L., \& Albert, M. S. (1996). Conscious recollection and the human hippocampal formation: Evidence from positron emission tomography. Proceedings of the National Academy of Science, 93, 321-325.

Schacter, D. L., Buckner, R. L., Koutstaal, W., Dale, A. M., \& Rosen, B. R. (1997). Late onset of anterior prefrontal activity during true and false recognition: An event-related fMRI study. Neuroimage, 6, 259-269.

Schacter, D. L., Curran, T., Galluccio, L., Milberg, W. P., \& Bates, J. F. (1996). False recognition and the right frontal lobe: A case study. Neuropsychologia, 34, 793-808.

Schacter, D. L., Savage, C. R., Alpert, N. M., Rauch, S. L., \& Albert, M. S. (1996). The role of hippocampus and frontal cortex in age-related memory changes: A PET study. Neuroreport, 7 , $1165-1169$.

Senkfor, A., \& Van Petten, C. (1998). Who said what: An event-related potential investigation of source and item memory. Journal of Experimental Psychology: Learning, Memory, and Cognition, 24, 1005-1025.

Shallice, T., \& Burgess, P. W. (1991). Deficits in strategy application following frontal lobe damage in man. Brain, 114, 727-741.

Shallice, T., Fletcher, P., Frith, C. D., Grasby, P., Frackowiak, R. S., \& Dolan, R. J. (1994). Brain regions associated with acquisition and retrieval of verbal episodic memory. Nature, 368, 633-635.

Shimamura, A. P. (1995). Memory and the frontal lobe. In M. S. Gazzaniga (Ed.), The cognitive neurosciences (pp. 803-813). Cambridge, MA: MIT Press.

Shimamura, A. P., Janowsky, J. S., \& Squire, L. R. (1990). Memory for the temporal order of events in patients with frontal lobe lesions and amnesic patients. Neuropsychologia, 28, 803-814.

Shimamura, A. P., Jurica, P. J., Mangels, J. A., Gershberg, F. B., \& Knight, R. T. (1995). Susceptibility to memory interference effects following frontal lobe damage: Findings from tests of paired-associate learning. Journal of Cognitive Neuroscience, 7 , $144-152$.

Smith, M. E. (1993). Neurophysiological manifestations of recollective experience during recognition memory judgments. Journal of Cognitive Neuroscience, 5, 1-13. 
Smith, M. E., \& Guster, K. (1993). Decomposition of recognition memory event-related potentials yields target, repetition, and retrieval effects. Electroencephalography and Clinical Neurophysiology, 86, 335-343.

Smith, M. E., \& Halgren, E. (1989). Dissociation of recognition memory components following temporal lobe lesions. Journal of Experimental Psychology: Learning, Memory, and Cognition, $15,50-60$.

Smith, M. E., Stapleton, J. M., \& Halgren, E. (1986). Human medial temporal lobe potentials evoked in memory and language tasks. Electroencephalography and Clinical Neurophysiology, 63, 145-159.

Snodgrass, J. G., \& Corwin, J. (1988). Pragmatics of measuring recognition memory: Applications to dementia and amnesia. Journal of Experimental Psychology: General, 117, 34-50.

Squire, L. R., Ojemann, J. G., Miezin, F. M., Petersen, S. E., Videen, T. O., \& Raichle, M. E. (1992). Activation of the hippocampus in normal humans: A functional anatomical study of memory. Proceedings of the National Academy of Science, 89, $1837-1841$.

Stuss, D. T., Alexander, M. P., Palumbo, C. L., Buckle, L., Sayer, L., \& Pogue, J. (1994). Organizational strategies of patients with unilateral or bilateral frontal lobe injury in word learning tasks. Neuropsychology, 8, 355-373.

Swick, D. (1998). Effects of prefrontal lesions on lexical processing and repetition priming: An ERP study. Cognitive Brain Research, 7, 143-157.

Swick, D., \& Knight, R. T. (1995). Contributions of right inferior temporal-occipital cortex to visual word and nonword priming. NeuroReport, 7, 11-16.

Swick, D., \& Knight, R. T. (1996). Is prefrontal cortex involved in cued recall? A neuropsychological test of PET findings. Neuropsychologia, 34, 1019-1028.

Swick, D., \& Knight, R. T. (1997). Event-related potentials differentiate the effects of aging on word and nonword repetition in explicit and implicit memory tasks. Journal of Experimental Psychology: Learning, Memory, and Cognition, 23, 123-142.

Swick, D., \& Knight, R. T. (1998). Lesion studies of prefrontal cortex and attention. In $\mathrm{R}$. Parasuraman (Ed.), The attentive brain (pp. 143-162). Cambridge, MA; MIT Press.

Swick, D., Kutas, M., \& Neville, H. (1994). Localizing the neural generators of event-related brain potentials. In A. Kertesz (Ed.),
Localization and neuroimaging in neuropsychology (pp. 73121). San Diego, CA: Academic Press.

Trott, C. T., Friedman, D., Ritter, W., \& Fabiani, M. (1997). Item memory and source memory: Differential age effects revealed by event-related potentials. NeuroReport, 8, 3373-3378.

Tulving, E. (1983). Elements of episodic memory. New York: Oxford University Press.

Tulving, E., Kapur, S., Craik, F. I. M., Moscovitch, M., \& Houle, S. (1994). Hemispheric encoding/retrieval asymmetry in episodic memory: Positron emission tomography findings. Proceedings of the National Academy of Science, 91, 2016-2020.

Tulving, E., Kapur, S., Markowitsch, H. J., Craik, F. I. M., Habib, R., \& Houle, S. (1994). Neuroanatomical correlates of retrieval in episodic memory: Auditory sentence recognition. Proceedings of the National Academy of Science, 91, 2012-2015.

Van Petten, C., \& Senkfor, A. J. (1996). Memory for words and novel visual patterns: Repetition, recognition, and encoding effects in the event-related brain potential. Psychophysiology, 33, 491-506.

Wilding, E. L., Doyle, M. C., \& Rugg, M. D. (1995). Recognition memory with and without retrieval of context: An event-related potential study. Neuropsychologia, 33, 743-767.

Wilding, E. L., \& Rugg, M. D. (1996). An event-related potential study of recognition memory with and without retrieval of source. Brain, 119, 889-905.

Woods, D. L., \& Knight, R. T. (1986). Electrophysiologic evidence of increased distractibility after dorsolateral prefrontal lesions. Neurology, 36, 212-216.

Yonelinas, A. P., \& Jacoby, J. J. (1995). The relation between remembering and knowing as bases for recognition: Effect of size congruency. Journal of Memory and Language, 34, 622643.

Zola-Morgan, S., \& Squire, L. R. (1993). Neuroanatomy of memory. Annual Review of Neuroscience, 16, 547-563.

Received February 11, 1998

Revision received August 17, 1998 Accepted August 18, 1998 